\title{
Letters
}

Website: www.bmj.com

Email: letters@bmj.com

\section{Management of hypertension}

\section{Ideal body weight is not realistic goal for} lifestyle intervention

EDITOR-Ramsay et al have produced a clear and authoritative document with their recent guidelines for the treatment of hypertension. ${ }^{1}$ The section on lifestyle modification, however, includes the statement that weight loss to achieve an ideal body weight will lower blood pressure.

Although this is undoubtedly true, it undermines most recent guidelines that recognise the practical near impossibility of achieving ideal body weight in most obese subjects $^{2-4}$ and evidence that suggests that more modest (and achievable) reductions in weight of $5-10 \%$ of body weight can be effective at lowering systolic and diastolic blood pressure in the range of 4-7 and 3-6 $\mathrm{mm} \mathrm{Hg}$ respectively. ${ }^{5}$ It should be made explicit in the guidelines that this degree of weight loss is likely to be beneficial in reducing cardiovascular risk, rather than perpetuating the myth that "ideal" body weight is a realistic goal of lifestyle modification in overweight and obese subjects.

John Wilding senior lecturer in medicine j.p.h.wilding@liv.ac.uk

Gareth Williams professor

University Clinical Departments, University

Hospital Aintree, Liverpool L9 7AL

Competing interests: Both authors have received honoraria for speaking at lectures, consultancy fees, and grant support from a number of companies that produce, or are developing, pharmacological treatments for obesity.

1 Ramsay LE, Williams B, Johnston GD, MacGregor GA, Poston L, Potter JF, et al. British Hypertension Society guidelines for hypertension management 1999: summary. BMJ 1999;319:630-35. (4 September.)

2 Royal College of Physicians. Clinical management of overweight and obese patients, with particular reference to the use of drugs. London: Royal College of Physicians, 1998.

3 Obesity in Scotland: integrating prevention with weight management. Edinburgh: SIGN, 1996.

4 Clinical guidelines on the identification, evaluation and treatment of overweight and obesity in adults. Bethesda, MD:National Institutes of Health, 1998.

5 Trials of Hypertension Collaborative Research Group. Effects of weight loss and sodium reduction intervention in Effects of weight loss and sodium reduction intervention in
blood pressure incidence in overweight people with highblood pressure incidence in overweight people with high-
normal blood pressure: the trials of hypertension prevennormal bheod pressure: the trials of hypertension Intern 1997;157:657-67.
tion, phase

\section{Patients from ethnic minorities are at greater risk}

EDITOR-The latest guidelines by the British Hypertension Society aim to address the incomplete detection, treatment, and control of hypertension prevalent across all sections of the community. ${ }^{1}$ The emphasis on the assessment and reduction of cardiovascular risk rather than just the maintenance of an optimal blood pressure is to be welcomed.

One group at high risk is, however, hardly mentioned. Sections of the ethnic community, particularly Afro-Caribbeans and South Asians, are at greatly increased risk of end organ damage owing to hypertension. They also exhibit an increased incidence of concomitant cardiovascular risk factors such as diabetes and obesity.

The guidelines note that differences in average response between drug groups are related to ethnic group, but the reader is simply referred to the full report. ${ }^{2}$ Although the British Hypertension Society sees ethnic background as neither a possible nor a compelling indication for any particular class of treatment, it supports the view that such patients are best treated with monotherapy with thiazide or a calcium antagonist. ${ }^{3}$ This rarely lowers blood pressure below 140/80 $\mathrm{mm} \mathrm{Hg}$. It also causes deleterious activation of the renin angiotensin system. Combining a thiazide or calcium antagonist with either an angiotensin converting enzyme inhibitor or a $\beta$ blocker helps preserve neurohormonal balance. This is also far more efficacious in terms of response rates, blood pressure reduction, and, presumably, reduced cardiovascular risk.

The increasingly recognised benefits of angiotensin converting enzyme inhibitors, both in terms of the reduction of cardiovascular risk and the prevention of the development and progression of diabetes, were highlighted in the heart outcomes prevention evaluation study recently reported at the European Society of Cardiology. ${ }^{5}$ These effects seem independent from and additive to the benefits of blood pressure reduction. Extrapolation of the evidence from the trials of $\beta$ blockade after myocardial infarction and in heart failure suggests analogous benefits for $\beta$ blockers. Not to use treatment based around an angiotensin converting enzyme inhibitor or a $\beta$ blocker in patients at greatest cardiovascular risk is to deprive those who would be expected to benefit most.

The rationale for first line combination treatment in ethnic patients is clear, the evidence in favour persuasive, and the implications in terms of reductions in morbidity and mortality considerable. The guidelines missed an opportunity to address the disparity in treatment and outcomes in an important sector of the community. In this area, at least, it seems that the guidelines will be rapidly superseded.

Garfield Drummond specialist registrar in clinical pharmacology

Department of Clinical Pharmacology, Division of Medicine and Therapeutics, Leicester Royal Infirmary, Leicester University, Leicester LE2 7LX

Competing interests: None declared.

1 Ramsay LE, Williams B, Johnston GD, MacGregor GA, Poston L, Potter JF, et al. British Hypertension Society guidelines for hypertension management 1999: summary. BMJ 1999;319:630-35. (4 September.)

2 Ramsay LE, Williams B, Johnston GD, MacGregor GA,

Ramsay LE, Williams B, Johnston GD, MacGregor GA, Poston L, Potter JF, et al. Guidelines for the management of hypertension: report of the third working party of the British Hyper

3 Gibbs CR, Beevers GD, Lip GY. The management of hypertensive disease in black patients. QJ Med 1999;92: $187-92$

4 Radevski IV, Valtchanova SP, Candy GP, Tshele EF, Sareli P. Comparison of acebutolol with and without hydrochlorothiazide versus Carvedilol with and without hydrochlorothiazide in black patients with mild to moderate systemic hypertension. Am J Cardiol 1999;84:70-5.

5 Kleinert S. HOPE for cardiovascular disease prevention with ACE-inhibitor ramipril. Heart outcomes prevention evaluation. Lancet 1999;354:841.

\section{Guidelines have serious weaknesses}

EDITOR-It is unfortunate that at a time when general practitioners are crying out for clear, practical, evidence based advice the $B M J$ should publish the British Hypertension Society's guidelines. ${ }^{1}$ The guidelines (and their sister document ${ }^{2}$ ) contain many references that, taken together, show that it

\section{Advice to authors}

We prefer to receive all responses electromically, sent either directly to our website or to the editorial office as email or on a disk. Processing your letter will be delayed unless it arrives in an electronic form.

We are now posting all direct submissions to our website within 24 hours of receipt and our intention is to post all other electronic submissions there as well. All responses will be eligible for publication in the paper journal.

Responses should be under 400 words and relate to articles published in the preceding month. They should include $\leqslant 5$ references, in the Vancouver style, including one to the BMJ article to which they relate. We welcome illustrations.

Please supply each author's current appointment and full address, and a phone or fax number or email address for the corresponding author. We ask authors to declare any competing interest. Please send a stamped addressed envelope if you would like to know whether your letter has been accepted or rejected.

Letters will be edited and may be shortened.

www.bmj.com

letters@bmj.com 
Implications of British Hypertension Society's guidelines: numbers of patients (percentages of age group) needing treatment on average general practitioner's list of 1800; cardiovascular events prevented per five years of treatment; five year numbers needed to treat (NNT)

\begin{tabular}{|c|c|c|c|c|c|c|c|c|}
\hline \multirow[b]{2}{*}{ Age } & \multicolumn{4}{|c|}{ Men } & \multicolumn{4}{|c|}{ Women } \\
\hline & $\begin{array}{l}\text { No }(\%) \text { needing annual } \\
\text { serum lipid estimation* }\end{array}$ & $\begin{array}{c}\text { No }(\%) \text { needing } \\
\text { treatment }\end{array}$ & $\begin{array}{c}\text { Events prevented } \\
\text { per } 5 \text { years } †\end{array}$ & $\begin{array}{l}\text { Five year } \\
\text { NNT }\end{array}$ & $\begin{array}{l}\text { No }(\%) \text { needing annual } \\
\text { serum lipid estimation* }\end{array}$ & $\begin{array}{c}\text { No }(\%) \text { needing } \\
\text { treatment }\end{array}$ & $\begin{array}{c}\text { Events prevented } \\
\text { per } 5 \text { years } \dagger\end{array}$ & Five year NNT \\
\hline 16-24 & $21(20)$ & $1(1)$ & 0 & 1535 & $5(5)$ & $0(0)$ & None treated & None treated \\
\hline $25-34$ & $34(23)$ & $4(3)$ & 0 & 161 & $9(6)$ & $0(0)$ & None treated & None treated \\
\hline $35-44$ & $29(24)$ & $8(6)$ & 0.2 & 46 & $12(10)$ & $3(2)$ & 0 & 79 \\
\hline 45-54 & $38(32)$ & $32(28)$ & 1.0 & 31 & $25(22)$ & $19(17)$ & 0.5 & 39 \\
\hline $55-64$ & $35(40)$ & $50(57)$ & 2.2 & 22 & $30(33)$ & $48(53)$ & 1.7 & 28 \\
\hline $65-74$ & $25(35)$ & $49(68)$ & 3.2 & 15 & $31(36)$ & $59(68)$ & 3.2 & 18 \\
\hline$\geqslant 75$ & $16(36)$ & $32(72)$ & 2.7 & 12 & $27(32)$ & $66(79)$ & 4.8 & 14 \\
\hline Total aged $16-74$ & $183(28)$ & $144(22)$ & 6.7 & 22 & $112(17)$ & $128(20)$ & 5.5 & 23 \\
\hline
\end{tabular}

Some totals do not add up owing to rounding.

*Guidelines indicate that patients with systolic blood pressure $\geqslant 140$ but $<160 \mathrm{~mm} \mathrm{Hg}$ should have annual serum lipid estimations to assess cardiovascular risk.

†Based on assumption that treatment reduces risk by $33 \%$.

is time to drop the "threshold blood pressure" paradigm and adopt an approach based on estimated cardiovascular risk. The authors ignore the evidence they have amassed and promote the continued use of the "threshold blood pressure" paradigm. They are able to do this only by joining the two paradigms in a forced marriage. The result of this miscegenation is epitomised by the complex and confusing "blood pressure threshold and drug treatment in hypertension" algorithm.

The guidelines have four serious weaknesses. Firstly, they make no reference to patient preferences. Why choose a 10 year risk threshold of $15 \%$ ? Are we sure that patients are happy to take a treatment for 10 years, knowing that 19 out of 20 will derive no benefit?

Secondly, they make no reference to resources, the most important of which is the workload of general practitioners. Data are available on the distribution of blood pressure and smoking, ${ }^{3}$ diabetes, ${ }^{4}$ and serum concentrations of cholesterol ${ }^{5}$ in the English population. From these data it is estimated that an average general practitioner list includes 272 patients aged under 75 years who would be eligible for treatment (table). In order to treat these patients, that general practitioner would have to devote about four hours a week to their ongoing management. Alternatively, if each primary care group ran a dedicated hypertension service, it would employ six full time hypertension specialists (data sources and calculations are available from us).

Thirdly, the guidelines provide no estimate of the benefits that might result because of this treatment. Without at least an estimate, it is impossible for a general practitioner to decide whether investing time and energy in hypertension control is worth while. If a general practitioner dedicates about 200 hours a year to managing these 272 patients, he or she will at best prevent two cardiovascular events (myocardial infarction, cardiovascular events, and new episodes of ischaemic heart disease) (table).

Fourthly, no practical advice is given on how general practitioners can identify patients at high risk for further evaluation. Under the most conservative interpretation of the guidelines, 300 patients will require annual serum lipid estimations (table).

These are not guidelines that can help general practitioners through the minefield of diagnosis and management of cardiovascular risk factors; they are guidelines that will lead to a labyrinth of screening and treatment in which even the most seasoned practitioner will get lost.

Tom Marshall clinical lecturer in public health medicine

Andrew Rouse senior lecturer in public health medicine

Department of Public Health and Epidemiology, University of Birmingham, Birmingham B15 2TT

Competing interests: None declared.

1 Ramsay LE, Williams B, Johnston GD, MacGregor GA, Poston L, Potter JF, et al. British Hypertension Society Poston L, Potter JF, et al. British Hypertension Society guidelines for hypertension managem 1999:319:630-35. (4 September)

2 Wood D, Durrington P, Poulter N, McInnes G, Rees A, Wray R. Joint British recommendations on prevention of coronary heart disease in clinical practice. Hear 1998;80:S1-29.

3 Department of Health. Health survey for England 1996. London: Stationery Office, 1998.

4 Office for National Statistics. Key health statistics from general practice: analyses of morbidity and trends, 1996. London: ONS, 1998

5 Unwin N, Thomson R, O'Bryne AM, Armstrong H, Laker ML. The implications of applying widely accepted cholesterol screening and management guidelines to a British adult population: results from a cross sectional study of cardiovascular disease and risk factors. BMJ 1998;317: 1125-30.

\section{Guidelines do not consider workload implications in primary care}

EDITOR-The new joint British societies' recommendations on prevention of coronary heart disease seem to have been introduced without any consideration of workload implications for general practice. ${ }^{12}$ By lowering the threshold for treatment they have created huge numbers of new hypertensive patients. Each patient will require assessment, workup, and several appointments before control is acceptable to both clinician and patient.

A conservative estimate is that, on average, newly identified hypertensive patients will need four appointments a year, especially in the first 12 months. How many extra patients each general practitioner and practice nurse will be expected to see each week is difficult to quantify. In addition to new hypertensive patients requiring treatment there are established patients who are no longer adequately controlled and new hyperlipidaemic patients.

A partial solution is that practices that are committed to the guidelines be given the extra funding needed (mainly a limited increase in the hours of practice nurses). Otherwise surgeries will spend increasing amounts of time and resources on patients having preventive care at the expense of those who wish to seek advice because they feel ill. The joint societies seem to have insufficiently consulted general practitioners when developing their guidelines. General practitioners tend to blame their excessive and sometimes demoralising workloads on "high patient demand." It may be that on this occasion "high professorial demand" is to blame.

John Eisenberg general practitioner

Macklin Street Surgery, Derby DE1 1JX

derby.gpvts@virgin.net

Competing interests: None declared.

1 Ramsay LE, Williams B, Johnston GD, MacGregor GA, Poston L, Potter JF, et al. British Hypertension Society guidelines for hypertension management 1999: summary. BM) 1999;319:630-35. (4 Septenber.)

2 Wood D, Durrington P, Poulter N, McInnes G, Rees A, Wray R. Joint British recommendations on prevention of coronary heart disease in clinical practice. Heart 1998;80:S1-29.

\section{Non-medical remedies should be considered first}

EDitor-With reference to Psaty and Furberg's editorial on managing hypertension in the United Kingdom, ${ }^{1}$ I am amazed that there was no attempt to bring down people's blood pressure by reducing salt intake and encouraging daily strengthening, cardiovascular, and stretching exercise. Whereas the medical profession clearly is trained to dish out drugs there is a body of scientific evidence-see www.pritikin.comthat shows that diet and exercise are very effective at reducing hypertension.

I wish Britain's medical profession would become more aggressive in preventive medicine and in treating the whole person. It is not a question of money but one of attitude. A Californian on a somewhat misty visit to the United Kingdom (east London suburbs and Yorkshire), I was the only one out jogging before work, and people looked at me as if I was a freak from 
another planet. Many people have hypertension.

Angela Hey consultant

Areva International, Portola Valley, CA 94028, USA amhey@areva.com

Competing interests: None declared.

1 Psaty B, Furberg CG. British guidelines on managing hypertension. BMJ 1999;319:589-90. (4 September.)

Evidence shows that calcium antagonists reduce cardiovascular end points in diabetic patients

EdIToR-The British Hypertension Society guidelines for the management of hypertension provide an excellent summary of the recently published randomised controlled trials and provide a template for all doctors who treat patients with hypertension. ${ }^{1}$ The accompanying editorial by Psaty and Furberg did no justice to the guidelines. ${ }^{2}$ I take particular issue with the line in the editorial stating that diabetes would have been a compelling or possible contraindication to calcium antagonists.

The studies cited by Psaty and Furberg in diabetic patients include the appropriate blood pressure control in diabetes trial, the premature termination of which was heavily criticised owing to the small number of events on which this decision was based and the possibility that the observations were due to chance. ${ }^{3}$ The second study cited was the fosinopril versus amlodipine cardiovascular events trial, which also received considerable criticism because its findings have been based on a small number of events. Furthermore, $56.9 \%$ of patients in this study required both a calcium antagonist and angiotensin converting enzyme inhibitors to control blood pressure, and fewer events were seen in the patients having dual treatment, suggesting that this combination of treatments is appropriate in diabetic patients.

The results of these studies have been refuted by the studies into systolic hypertension in Europe and optimal treatment for hypertension, both of which have shown highly beneficial effects of treatment based on calcium antagonists for cardiovascular events in diabetic subjects. ${ }^{45}$ The evidence from randomised controlled studies thus shows that calcium antagonists reduce cardiovascular end points in diabetic patients, and the British Hypertension Society guidelines correctly state that they are not contraindicated in diabetic subjects.

Tahseen A Chowdhury lecturer in medicine Heartlands Diabetes Centre, Birmingham Heartlands Hospital, Birmingham B9 5SS T.A.Chowdhury@bham.ac.uk

Competing interests: None declared.

1 Ramsay LE, Williams B, Johnston GD, MacGregor GA, Poston L, Potter JF, et al. British Hypertension Society guidelines for hypertension management 1999: summary. BMJ 1999;319:630-35. (4 September.)

2 Psaty BM, Furberg CD. British guidelines on managing hypertension. BMJ 1999;319:589-590. (4 September.)

3 Parving HH. Calcium antagonists and cardiovascular risk in diabetes. Am J Cardiol 1998;82:42-44R.

4 Tuomilehto J, Rastenyte D, Birkenhager WM, Thijs L, Antikainen R, Bulpitt CJ, et al. Effects of calcium channel blockade in older patients with diabetes and systolic hypertension. N Engl J Med 1999;340:677-84.
5 Hansson L, Zanchetti A, Carruthers SG, Dahlöf B, Elmfeldt D, Julius S, et al. Effects of intensive bloodpressure lowering and low-dose aspirin in patients with hypertension: principal results of the hypertension optimal treatment (HOT) randomised trial. Lance 1998;351:1755-62.

\section{Optimal target pressure is not supported} by strength A evidence

EDIToR-The British Hypertension Society's guidelines should be commended for taking cost effectiveness into account, for example, in recommending low doses of cheap thiazides as first line drug treatment, or being on the conservative side in recommending the use of expensive statins. Furthermore, it is commendable that the evidence based guidelines for the north of England are used for grading the evidence supporting the recommendations.

The evidence supporting the suggested target blood pressures during antihypertensive treatment has been given the strongest recommendation $(\mathrm{A})$, indicating that the evidence stems from meta-analysis of randomised controlled trials or from at least one randomised controlled trial.

The recommendation that the optimal target blood pressure in non-diabetic people is $<140 / 85 \mathrm{~mm}$ Hgstems from the hypertension optimal treatment (HOT) trial. ${ }^{2}$ This particular finding was, however, not the result of a randomised controlled trial and should not be given strength A recommendation. The intention to treat analysis in the HOT trial was negative. The difference in any outcome measure between the three target groups $(90 \mathrm{~mm} \mathrm{Hg}, 85 \mathrm{~mm} \mathrm{Hg}$, or 80 $\mathrm{mm} \mathrm{Hg}$ ) was not significant. The patients achieving the "optimal" $82.6 \mathrm{~mm} \mathrm{Hg}$ are not the same as those who were randomised to the lowest diastolic blood pressure but are a mixture of patients from all three groups, probably dominated by those patients who responded most effectively to the intervention. The analysis of the achieved blood pressure is purely observational, treating the total study population as one single cohort, and should therefore be given a strength $\mathrm{C}$ recommendation.

Hogne Sandvik general practitioner

Department of Public Health and Primary Health Care, University of Bergen, N-5009 Bergen, Norway hogne.sandvik@isf.uib.no

Competing interests: None declared.

1 Ramsay LE, Williams B, Johnston GD, MacGregor GA, Poston L, Potter JF, et al. British Hypertension Society guidelines for hypertension management 1999: summary. BMJ 1999-319.630-35. (4 September)

2 Hansson I Zanchetti A Carruthers SG, Dahlöf B, Hansson L, Zanchetti A, Carruthers SG, Dahlof Elmfeldt D, Julius S, et al. Effects of intensive blood pressure lowering and low-dose aspirin in patients with hypertension: principal results of the hypertension optimal treatment (HOT) randomised trial. Lance

\section{"Mortality" is preferable to "major disease end points"}

EDITOR-In their editorial on the new British Hypertension Society guidelines for managing hypertension, Psaty and Furberg demand evidence that recommended drug treatments reduce major disease end points, such as myocardial infarction, stroke, and heart failure. ${ }^{1}$ Although this would be an improve- ment on evidence that they lowered blood pressure, it is insufficient to justify their use. If a drug were shown to reduce cardiac deaths but had no effect on all cause mortality, I would be reluctant to take it, particularly if the displaced mortality was in the form of increased suicide and homicide-presumably as a consequence of the drug's side effects.

In reading reports of randomised trials of drugs claiming success, I first look for the effect on all cause mortality. If that is not significantly negative or, worse still, not even revealed, I pass on. It saves a lot of reading.

The area of medicine in which treatment has become completely detached from clinical end points is HIV infection. Drugs with the most devastating and frequent side effects are now given to symptomless mothers and babies for no better reason than that they reduce the incidence of scoring positively on an HIV test.

Michael Stewart statistical consultant

2 Lesley Court, Strutton Ground, London, SW1P 2HZ

Competing interests: None declared.

1 Psaty B, Furberg C. British guidelines on managing hypertension. BMJ 1999; 319:589-590. (4 September.)

\section{Trials showing no reduction in mortality} do not receive same exposure

EDITOR-The expert guidelines we are advised to follow are not based on the people I look after as a general practitioner, and the details given in the guidelines are not patient friendly. ${ }^{1}$ I would like to know the numbers needed to treat, and when the guidelines say deaths prevented I assume they mean deaths postponed, as we all die. How long are the deaths prevented for, what do the patients die of if it is not a consequence of their hypertension, and could we not have prevented that also?

Around September 1999 a fact sheet from the British Heart Foundation advised that blood pressure should be reduced to below 125/75 mm $\mathrm{Hg}$ in a diabetic patient with proteinuria. I believe that if I prescribed sufficient medication the side effects would probably be intolerable. I also question whether the number needed to harm would be lower than the numbers needed to treat. This information is not easily available. All trials seem to add yet more treatment when most of them are conducted on single interventions. The wisdom follows that they all can be added to give "extra" benefit. Sometimes I wonder if after a myocardial infarction the added value of aspirin, a $\beta$ blocker, a statin, an angiotensin converting enzyme inhibitor, and spirinolactone must make death impossible.

The most telling comment in the editorial accompanying the article was that no declaration of interest was published. ${ }^{2}$ The early hypertension trials conducted by the Medical Research Council showed a moderate benefit in some patients in treating hypertension. Instead we now have a bandwagon of multiple interventions at great cost. In my experience as a general practitioner actively participating in reach- 
ing hypertension targets, considerable anxiety and side effects are being generated by this drive. Over the years, there have been trials showing no reduction in mortality with various antihypertensive agents. Why do these not receive the same exposure?

NJ Sharvill general practitioner

Balmoral Surgery, Deal, Kent CT14 7AU

RoGi11111@aol.com

Competing interests: Dr Sharvill is taking part in the PRICCE project, in which hypertension targets are one area of study; if his practice meets all the area targets for diseases there will be a payment from the health authority.

1 Ramsay LE, Williams B, Johnston GD, MacGregor GA, Poston L, Potter JF, et al. British Hypertension Society guidelines for hypertension management 1999: summary. guidelines for hypertension managem

2 Psaty B, Furberg CG. British guidelines on managing hypertension. BMJ 1999;319:589-90. (4 September.)

\section{Authors' reply (Psaty and Furberg)}

EDITOR-In our editorial on the British Hypertension Society guidelines, we noted that the recommendations for drug treatment according to various compelling or possible indications were consensus based rather than evidence based. Although we do not advocate this approach, we did observe that if one were to favour the proliferation of items in a special indications table, diabetes would have been either a compelling or a possible contraindication to calcium channel blockers. We cited two small randomised clinical trials that directly compared calcium channel blockers and angiotensin converting enzyme inhibitors in patients with type 2 diabetes. ${ }^{12}$ In both, the use of calcium channel blockers was associated with a higher risk of cardiovascular events than treatment with angiotensin converting enzyme inhibitors.

Chowdhury responds that the results of these studies have been utterly refuted by the systolic hypertension in Europe (SystEur) and the hypertension optimal treatment (HOT) studies. ${ }^{34}$ We disagree. The Syst-Eur paper, with a total of five stroke and seven cardiac events among diabetic patients in the active treatment group, represents a post hoc subgroup analysis that should be interpreted cautiously. Syst-Eur is a placebo controlled trial. Placebo controlled trials answer the question whether we should treat a condition such as isolated systolic hypertension. The benefits of treating this have been clear since 1991.

Randomised trials that directly compare two treatments are required to determine whether one is better than another. Although cardiovascular events in the small comparative trials ${ }^{12}$ were a secondary end point, both comparative trials suggest that in patients with type 2 diabetes, angiotensin converting enzyme inhibitors are superior to calcium channel blockers in terms of preventing cardiovascular events.

In terms of antihypertensive therapy, the HOT study was robustly null. ${ }^{4}$ The differences in blood pressure among groups were small, and for the primary end point in intention to treat analyses there were no differences among the groups. We agree with
Sandvik that the observational analyses related to blood pressure within HOT should be graded $\mathrm{C}$ rather than $\mathrm{A}$.

Stewart prefers the outcome of total mortality. Few trials of antihypertensive treatments have been powered for the end point of total mortality. Cardiovascular and cerebrovascular events are often devastating illnesses that affect both quality and duration of life. Interpreting the morbidity outcomes in the context of total mortality is important. When mortality and morbidity outcomes go in different directions, the interpretation becomes problematic. Mortality and morbidity outcomes that go in the same direction are generally reassuring.

\section{Bruce M Psaty professor}

Departments of Medicine, Epidemiology and Health Services, University of Washington, Seattle, WA 88101 , USA

Curt D Furberg professor

Department of Health Sciences, Wake Forest University School of Medicine, Winston-Salem, NC, USA

Competing interests: The research reported in the editorial was supported in part by grants from the National Heart, Lung, and Blood Institute and the National Institute on Aging. Professor Psaty is a Merck/SER clinical epidemiology fellow (sponsored by the Merck Foundation and the Society for Epidemiologic Research, Baltimore). He has served on the events committee for a trial funded by Wyeth Ayerst. Professor Furberg receives research funding from Pfizer and Wyeth Ayerst and is consultant to Bristol Myers Squibb.

1 Estacio RO, Jeffers BW, Hiatt MR, Biggerstaff SL, Gifford N Schrier RW. The effect of nisoldipine as compared with enalapril on cardiovascular outcomes in patients with non-insulin-dependent diabetes and hypertension. $N$ Eng Med 1998;338:645-52

2 Tatti P, Pahor M, Byington RP, Di Mauro P, Guarisco R, Strollo G, et al. Outcome results of the fosinopril versu amlodipine cardiovascular events trial (FACET) in patients with hypertension and non-insulin dependent diabetes mellitus. Diabetes Care 1998;21:597-603.

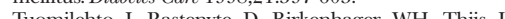
Tuomilehto J, Rastenyte D, Birkenhager WH, Thijs I Antikainen R, Bulpitt CJ, et al. Effects of calcium-channe blockade in older patients with diabetes and systolic (1)

4 Hansson L, Zanchetti A, Carruthers SG, Dahlöf B, Elmfeldt D, Julius S, et al. Effects of intensive bloodpressure lowering and low-dose aspirin in patients wit hypertension: principal results of the hypertension optimal treatment (HOT) randomised trial. Lance 1998;351:1755-62.

5 SHEP Cooperative Research Group. Prevention of stroke by antihypertensive drug treatment in older persons with isolated systolic hypertension: final results of the systolic hypertension in the elderly program (SHEP). JAMA 1991;265:3255-64.

\section{Authors' reply (Ramsay et al)}

EDITOR-We accept Wilding's proposal that we should have recommended weight loss towards (rather than to achieve) ideal body weight in line with the graded benefits in reduction of blood pressure which result from lesser degrees of weight loss as reported in the full version of the guidelines.

Drummond is correct that there is a high prevalence of hypertension and cardiovascular disease in African-Caribbean and South Asian communities, but space constraints prevented discussion of specific subgroups (for example, elderly or diabetic patients) except in the full version of the paper. ${ }^{1} \mathrm{He}$ was incorrect to say that we recommend monotherapy for any specific group of patients. On the contrary, we emphasised the likelihood that more than one drug was likely to be required to achieve optimal control of blood pressure in most patients. Moreover, Drummond's certainty regarding the benefits of angiotensin converting enzyme inhibition for all patients is unfounded, as is his assertion that the still unpublished benefits of angiotensin converting enzyme inhibition in the heart outcomes prevention evaluation (HOPE) trial are necessarily independent from and additive to the benefits of a reduction in blood pressure. His conclusions are not supported by the results of the Swedish trial in old patients with hypertension 2 (STOP 2 trial). ${ }^{2}$ Furthermore, his alternative proposal that treatment should be based around a $\beta$ blocker is not commensurate with meta-analysed trial evidence of hypertension management in elderly people.

Turning to the serious weaknesses identified by Marshall and Rouse: successful application of the guidelines will prevent not only coronary events but also strokes, and treated patients will also develop less atherosclerosis, left ventricular hypertrophy, dementia, and heart failure. We believe that patients, if fully informed rather than confused by inappropriate statistics, would choose treatment under these circumstances.

The implications of the guidelines for resources were discussed under "Implementation," and the British Hypertension Society has established an implementation group with input from general practice and nursing to address this important issue. Nevertheless, we strongly believe that guidelines should reflect best practice according to the best available evidence. These guidelines were developed mindful of the poor record of the NHS in preventing premature cardiovascular morbidity and mortality, and best evidence clearly shows the benefit of the recommended interventions.

To ensure treatment is rationally targeted at those with highest calculated cardiovascular risk, we provided practical advice for the identification of high risk patients in the section headed "Evaluation of hypertensive patients." This approach has been widely applauded and ensures the most effective use of resources. The measurement of lipids is correctly incorporated into this and all other accurate cardiovascular risk assessments.

Eisenberg's assertion that the guidelines have created huge numbers of hypertensive patients is not valid. We have merely highlighted the fact that blood pressure is a continuous variable in the calculation of cardiovascular risk. Those at highest risk will thus benefit from treatment at lower thresholds. We also hold the view that primary prevention of cardiovascular disease is preferable to, if less dramatic than, treating established heart disease and stroke, which all too often is too late. We acknowledged an important role for general practitioners and nurses in achieving this objective and the development of the guidelines benefited from their input.

Hey has apparently not read the guidelines summary since both exercise and salt restriction were discussed and highlighted in the article, although we did not 
specifically endorse jogging in east London suburbs or Yorkshire as being particularly beneficial.

We support Chowdhury's criticism of the editorial by Psaty and Furberg that accompanied the guidelines, and we agree with Sandvik's careful and incisive comments that the evidence from the hypertension optimal treatment (HOT) trial is less than ideal. We reassert our belief, however, that the HOT trial provided some guidance and reassurance and the best evidence to date on targets for blood pressure.

We hope that Stewart's approach to interpreting trials solely on the basis of all cause mortality results, irrespective of power consideration and a priori hypotheses, will not be emulated by others. Furthermore, in response to Sharvill's report of his experience, we agree that side effects of treatment can be tiresome and troublesome, but in our clinical practice they are perhaps less troublesome than strokes, heart attacks, and heart failure owing in part to suboptimal management of hypertension and associated cardiovascular risk factors. We are not aware of the trials that he says showed no reduction in mortality with various antihypertensive agents.

Lawrence E Ramsay professor of clinical pharmacology and therapeutics

University of Sheffield, Sheffield S10 2TN

Bryan Williams professor of medicine

B Williamsbw17@leicester.ac.uk

John F Potter professor of medicine for the elderl

University of Leicester School of Medicine,

Leicester Royal Infirmary, Leicester LE2 7LX

G Dennis Johnston professor of clinical pharmacology Queen's University of Belfast, Belfast BT7 1NN

Graham A MacGregor professor of cardiovascular medicine

Department of Medicine, St George's Hospital, London SW17 0RE

Lucilla Poston professor of fetal medicine

Department of Obstetrics and Gynaecology, St Thomas's Hospital, London SE1 7EH

Neil R Poulter director, cardiovascular studies unit Imperial College School of Medicine, London W2 1NY

Gavin Russell consultant renal physician

North Staffordshire Royal Infirmary, Stoke on Trent ST4 7LN

Competing interests: None declared.

1 Ramsay LE, Williams B, Johnston GD, MacGregor GA Poston L, Potter JF, et al. Guidelines for management of hypertension: report of the third working party of the British Hypertension Society, 1999. J Human Hyperten 1999;13:569-92.

2 Hansson L, Lindholm LH, Ekbom T, Dahlö B, Lanke J, Schersten B, et al. Randomised trial of old and new antihypertensive drugs in elderly patients: cardiovascular mortality and morbidity the Swedish trial in old patients with hypertension-2 study. Lancet 1999;354:1751-6.

3 Messerli FH, Grossman E, Goldbourt U. Are beta-blockers efficacious as first line therapy for hypertension in the elderly? A systematic review. JAMA 1998;279:1903-7.

\section{Greenwich asthma study}

\section{Study's conclusions are premature}

EDITOR-Premaratne et al amassed an impressive amount of data in the Greenwich asthma study, ${ }^{1}$ but their outcome measures were unlikely to be able to detect an effect of their intervention. We think that they may have had an unreal expectation of the impact of the intervention in primary care, perhaps reflecting the absence of primary care researchers in the study team.

Designing large scale studies to test guidelines and educational interventions is not easy, particularly in inner city general practice. ${ }^{2}$ When testing whether nurses improve the care of patients with asthma in general practice, appropriate primary outcomes are measures of asthma control and health service use in the patients who consulted with the nurses rather than in the wider population of asthmatic patients. To judge the efficacy of the study nurses on their lack of effect on patients they did not see seems harsh, although asking asthmatic patients to attend review sessions is arguably part of their role. Though the mean square root of quality of life of the total asthmatic population is clearly an important (secondary) outcome, its importance may be obscure to many readers. Even the chosen secondary outcomes (steroid prescribing, attendance at accident and emergency departments, hospital admission) did not use as a denominator the patients who consulted during the study; neither is it clear that the study was sufficiently powered to detect differences for these variables. Focusing on the questionnaires or clinical records of these patients or a predetermined high risk group would have elucidated better the efficacy of the intervention.

Most studies showing the efficacy of education and guided self management have been carried out in hospital or outpatient populations - that is, among those with more severe disease. An intervention judged on its efficacy among all asthmatic patients registered in general practice, even those not receiving drug treatment, might be expected not to show a benefit. Intervention by a practice nurse is not necessarily appropriate for all asthmatic patients.

Few data are presented about the delivery of a complex health service intervention. For instance, interactive educational methods may be more effective than simple information transfer when implementing asthma guidelines. ${ }^{3}$ A qualitative analysis unpicking the black box of this educational programme would have been instructive. ${ }^{4}$ Without this it may be too early to suggest, as the authors do, that doctors might be more effective than nurses in educating patients with asthma.

Should the results of the study influence government policy? To conclude that primary care nurses trained by hospital specialist nurses are ineffective would be premature until other studies with more focused outcome assessment and cost effectiveness data have been reported.

Gene Feder senior lecturer

Chris Griffiths senior lecturer

c.j.griffiths@mds.qmw.ac.uk

Gill Foster research assistant

Shamoly Ahmed research assistant

Dorcas Maclaren researcher

Yvonne Carter professor of general practice

Department of General Practice and Primary Care, St Bartholomew's and the Royal London School of Medicine and Dentistry, Queen Mary and Westfield College, London E1 4NS
1 Premaratne UN, Sterne JA, Marks GB, Webb JR, Azima H, Burney PG. Clustered randomised trial of an intervention to improve the management of asthma: Greenwich asthma study. BMJ 1999;318:1251-5. (8 May.)

2 Griffiths CJ, Feder G. Clinician education-a key to implementing asthma guidelines? Quality in Health Care (in press)

3 Clark NM, Gong M, Schork MA, Evans D, Roloff D, Hurwitz M, et al. Impact of education for physicians on patient outcomes. Pediatrics 1998;101:831-6.

4 Bradley F, Wiles R, Kinmonth AL, Mant D, Gantley M. Development and evaluation of complex interventions in health services research: case study of the Southampton heart services rearch. case study of the Southampton tive Group. BMJ 1999;318:711-5.

\section{Authors' reply}

EDIToR-The Asthma Resource Centre was set up to improve the health of asthmatic people living in Greenwich. If it had achieved its objectives cost effectively it would have been an excellent model for other districts.

We did not measure the efficacy of the asthma nurses but their effectiveness. The idea behind the centre was to show that similar schemes could be applied across a district beyond the confines of a localised research environment. A key prerequisite for success was the nurses' ability to find and contact patients who would benefit.

The centre might have been more successful if it had targeted patients with severe asthma, but this was not part of the centre's remit or a stipulation of other programmes funded nationally in primary care. We did not suggest that doctors would be more effective than nurses in educating asthmatic patients but that the nurses might have been more effective if the general practitioners had been more active in the project.

Health related quality of life is a suitable primary outcome because it applies to all asthmatic patients, responds to change, and summarises the benefit perceived by patients. A small change would have shown that the programme was worth while, which is why the study was so large. Overall, $43 \%$ of patients had symptoms at least three times a week and $59 \%$ were woken by symptoms at least once every month. ${ }^{1}$ To exclude patients who were not receiving treatment would have been wrong as some of them might have benefited the most. We tested separately whether those who had the worst quality of life had benefited, and they had not.

In reply to Parnell and Cook, ${ }^{2}$ the nurses in the control and intervention practices were matched at the beginning of the trial for expertise in asthma education.

Parnell and Cook imply that the control group was tainted by the intervention. ${ }^{2}$ Our analysis showed that both groups were equally affected by local and national initiatives. The question being tested, however, was whether an asthma resource centre such as that in Greenwich would be more effective than any other initiatives. We conclude that other factors were much more effective, at least in increasing the prescription of steroids.

The evaluation study compared quality of life in those aged 16-50; the nurses saw only $17 \%$ of such patients with an estimated diagnosis of asthma from the respiratory 
questionnaire but $26 \%$ of all patients. We conducted an intention to treat analysis, and the failure to reach $83 \%$ of the treatment group is important. We agree with Parnell and Cook's implication that this made the success of the intervention unlikely, but the sample size was not small. It was large and representative of those whom the trial was intended to help.

A more detailed response is available on the $B M / \mathrm{s}$ website (www.bmj.com)

U N Premaratne consultant in communicable disease control

Bexley and Greenwich Health Authority, Bexleyheath, Kent DA7 6HZ

J A C Sterne senior lecturer

Department of Epidemiology and Community Medicine, University of Bristol, Bristol BS8 2PN

\section{P G J Burney professor}

Department of Public Health Sciences, King's

College London, London SE1 3QD

Peter.burney@kcl.ac.uk

G B Marks research fellow

Institute of Respiratory Medicine, University of

Sydney, New South Wales 2006, Australia

J R Webb consultant physician

Greenwich District Hospital, London SE10 9HE

1 Marks GB, Burney PGJ, Premaratne UN, Simpson J, Webb J. Asthma in Greenwich, UK: impact of the disease and current management practices. Eur Respir $J$ 1997;10:1224-9.

2 Parnell H, Cook NT. The Greenwich asthma study. BMJ 1999;319:709. (11 September.)

\section{$\beta$ Blockade after myocardial infarction}

\section{$\beta$ Blockers have key role in reducing} morbidity and mortality after infarction

EDitor-Freemantle et al show good evidence that long term $\beta$ blockade is an effective and well tolerated treatment that reduces mortality and morbidity in unselected patients after myocardial infarction. ${ }^{1}$ They present data for the end points all cause mortality and non-fatal reinfarction but make no specific reference to sudden death. They quote the results of 31 long term trials; we have been able to find data on sudden death in only 13 of these.

Sudden death is common and an important cause of death in the major long term trials after myocardial infarction. In the 13 trials that included data on sudden death the average incidence of sudden death in the placebo treated group was $51 \%$ (table). The corresponding figure in the groups treated with a $\beta$ blocker was $43 \%$. Although this suggests that $\beta$ blockers do reduce the risk of sudden death, these mean figures probably grossly underestimate the potential impact of $\beta$ blockers.

Average incidence of sudden death in long term trials comparing $\beta$ blockers with placebo after myocardial infarction

\begin{tabular}{lcccccccc} 
& \multicolumn{3}{c}{ Placebo treatment } & & \multicolumn{3}{c}{$\beta$ Blocker treatment } \\
\cline { 2 - 3 } & $\begin{array}{c}\text { Total No of } \\
\text { patients }\end{array}$ & $\begin{array}{c}\text { Total No } \\
\text { of deaths }\end{array}$ & $\begin{array}{c}\text { No }(\%) \text { of } \\
\text { sudden deaths }\end{array}$ & & $\begin{array}{c}\text { Total No of } \\
\text { patients }\end{array}$ & $\begin{array}{c}\text { Total No } \\
\text { of deaths }\end{array}$ & $\begin{array}{c}\text { No (\%) of } \\
\text { sudden deaths }\end{array}$ \\
\hline All $\beta$ blocker trials $^{1}$ & 6956 & 682 & $345(51)$ & & 7219 & 548 & $237(43)$ \\
\hline Norwegian timolol trial $^{2}$ & 939 & 152 & $95(63)$ & & 945 & 98 & $47(48)$ \\
\hline$\beta$ Blocker heart attack trial $^{3}$ & 1921 & 188 & $89(47)$ & & 1916 & 138 & $64(46)$
\end{tabular}

For interest, the table also shows results from the two largest trials, the Norwegian trial $^{2}$ and the $\beta$ blocker heart attack trial. The two drugs used in these trials, timolol $\beta$ blockers and seemed to reduce the risk of sudden death. In the two recently reported $\beta$ blocker heart failure studies the reduction prolol (in the cardiac insufficiency bisoprolol study $\mathrm{II}^{4}$ ) and metoprolol (in the metoprolol $\mathrm{CR} / \mathrm{XL}$ randomised intervention trial in congestive heart failure ${ }^{5}$ ) decreased sudden death rates by $42 \%$ and $41 \%$ respectively.

Therefore we agree that $\beta$ blockers have a key role in reducing the morbidity and mortality after myocardial infarction. There is also an important but less well recognised role for these agents in reducing the incidence of sudden death, which may account for half of the deaths in such patients.

Sarah L Nuttall research associate

sarah nuttall@msn.com

Veronica Toescu research associate

Martin J Kendall professor of clinical pharmacology Clinical Pharmacology Section, Department of

Medicine, Queen Elizabeth Hospital, Birmingham $\mathrm{B} 152 \mathrm{TH}$

Competing interests: Astra-Zeneca and several other drug companies that make $\beta$ blockers support the department's research.

1 Freemantle N, Cleland J, Young P, Mason J, Harrison J $\beta$ Blockade after myocardial infarction: systematic review June.)

2 Norwegian Multicentre Study Group. Timolol-induced reduction in mortality and reinfarction in patients surviving acute myocardial infarction. $N$ Engl $J$ Med 1981:304:801-7.

3 Beta Blocker Heart Attack Research Group. A randomized trial of propranolol in patients with acute myocardia infarction. I. Mortality results. JAMA 1982;247:1707-13.

4 CIBIS-II Investigators and Committees. The cardiac insufficiency bisoprolol study II (CIBIS-II): a randomised trial. Lancet 1999;353:9-13.

5 MERIT-HF Study Group. Effect of metoprolol CR/XL i chronic heart failure: metoprolol $\mathrm{CR} / \mathrm{XL}$ randomised intervention trial in congestive heart failure (MERIT-HF). Lancet 1999;353:2001-7.

\section{Absence of evidence is failure of research} policy

EDITOR-As I read through Freemantle et al's systematic review of $\beta$ blockade after myocardial infarction I looked particularly for evidence about the effectiveness of atenolol. ${ }^{1}$ In my practice atenolol is our first choice of $\beta$ blocker for hypertension, angina, and secondary prevention because it is convenient (once daily dose), cheap, and relatively free from side effects in most patients.

After the promising, if inconclusive, results of early short term trials of atenolol (pooled odds ratio $0.93 ; 95 \%$ confidence interval 0.85 to 1.02 ) it was frustrating to find that there were so few long term trials that and propranolol, are lipophilic non-selective in sudden death rates was even greater. Bisoand meta reoression analysis. BMI 1999:318:1730-7. (26 the results (odds ratio $1.02 ; 0.52$ to 1.99 ) were meaningless. The wide confidence intervals of the long term trials reflect the weight of $1.6 \%$ for long term trials of atenolol compared with $74.2 \%$ for the short term trials, and the authors rightly conclude that atenolol has been inadequately evaluated for long term use.

I and thousands of other general practitioners are thus faced with a dilemma. Should we switch patients from atenolol to propranolol (inconvenient dose or expensive sustained release preparations, plus more side effects) or timolol (also considerably more expensive than atenolol)? If we are to follow the available evidence then we should. On the other hand, absence of evidence of effectiveness is not the same as evidence of absence of effectiveness, and atenolol may, in reality, be as effective as propranolol or timolol. That we lack evidence one way or the other for the effectiveness of so ubiquitous a drug as atenolol in so important a clinical area as secondary prophylaxis of myocardial infarction represents a failure in research and development planning and policy.

Why was work on atenolol virtually abandoned after the promising early results? Was it just that newer compounds seemed more exciting than older ones? This seems unlikely, given that there is adequate evidence about propranolol, an even older drug. More probably the research agenda was driven not only by the clinical need for evidence but by the need for pharmaceutical companies to obtain evidence supportive of their products in order to increase sales. Perhaps atenolol, no longer under patent, was just too unprofitable to justify adequate research funding.

I am worried that the principles of evidence based medicine can be manipulated by pharmaceutical companies. They have the financial resources to carry out large randomised controlled trials, seeking outcomes that show their products in the most favourable light, while research on equally important questions remains underfunded.

Toby Lipman general practitioner

Westerhope Medical Group, Westerhope, Newcastle upon Tyne NE5 2LH

Toby@tobylipm.demon.co.uk

Competing interests: None declared.

1 Freemantle N, Cleland J, Young P, Mason J, Harrison J $\beta$ Blockade after myocardial infarction: systematic review and meta regression analysis. BMJ 1999;318:1730-7. (26 June.)

\section{Health professionals do not understand mathematical models}

EDITOR-The science commentary on herd immunity that accompanied the article by Panagiotopoulos et al on an increase in the occurrence of congenital rubella after immunisation seemed irrelevant. ${ }^{1}$ In this letter we attempt to explain the relevant issues.

Immunising a proportion of the population reduces the risk of infection (not neces- 
sarily disease) among those who are not immunised. This indirect protection from infection is termed herd immunity. It can be manifested in two different ways.

Firstly, if the level of vaccine coverage is high enough (the proportion of those who are susceptible is low enough) then transmission cannot be sustained, leading to elimination of the infection from the population. This threshold of coverage (occasionally termed the herd immunity threshold) is what Berger was attempting to explain in her commentary.

Secondly, if coverage is below the threshold then the infection will remain endemic. Individuals who have not been immunised will have a lower risk of infection because there will be fewer infectious people in the population. Thus, on average, if they become infected it will be at an older age. It is this which is critical to understanding the paper of Panagiotopoulos et al. Many infections that can be prevented by vaccination cause more severe clinical consequences in adults than in children'; examples include mumps, chickenpox, hepatitis $\mathrm{A}$, and rubella. After mass infant immunisations against such diseases the number of infections will decrease but those who become infected will, on average, be older and therefore have more serious disease. At low or intermediate levels of coverage it may be that the decrease in the incidence of infection is outweighed by the increase in the average seriousness of each case, resulting in more harm than good being done to public health. At higher levels of coverage the decrease in the incidence outweighs the increase in the average seriousness of each case and the programme is beneficial to public health.

The work of Panagiotopoulos et al is important because it is the first to show conclusively that an increase in the average age at infection occurring as a result of low levels of infant immunisation actually leads to more cases of severe disease than occurred before vaccinations were introduced. It is a shame that this had to be so. The warnings from mathematical models have been clear for many years. ${ }^{34}$ Perhaps a lack of understanding of the models among health professionals has contributed to their reluctance to adopt the recommendations generated by the models. Education of decision makers is clearly important.

W J Edmunds health economist jedmunds@phls.nhs.uk

N J Gay mathematical modeller

PHLS Communicable Disease Surveillance Centre, London NW9 5EQ

1 Panagiotopoulos T, Antoniadou I, Valassi-Adam E. Increase in congenital rubella occurrence after immunisation in Greece: retrospective survey and systematic review [with science commentary by A Berger]. BM] 1999;319:1462-6. (4 December.)

2 Miller E, Gay N. Effect of age on outcome and epidemiology of infectious diseases Biologicals 1997;25:137-42.

3 Knox EG. Theoretical aspects of rubella vaccination. Rev Infect Dis 1985;7(suppl 1):194-7S

4 Anderson RM, Grenfell BT. Quantitative investigations of different rubella vaccination policies for the control of diferent rubela congenital rubella syndrome (CRS) in the United
Kingdom. J Hyg 1986;96:305-33.
Inequalities in health

continue to grow despite government's pledges

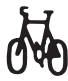

EDITOR-Yamey summarises our report showing that mortality differentials increased dramatically in Britain during 1981-95 in line with equally dramatic increases in income inequality. ${ }^{1}$ The current government is committed to reducing health inequalities: "Our ambition is to do something that no government-Tory or Labour-has ever done. Not only to improve the health of the nation, but also to improve the health of the worst off at a faster rate."

We suggest that on current evidence the government is doing little to reduce inequalities in material standards of living, although previous governments of all political parties have on occasion managed to do so." The Department of Health has denied this shortcoming and pointed out that our mortality data went up to 1995 and say nothing about the current government. ${ }^{4}$ While we acknowledged that mortality data were at that time available only up to $1995,{ }^{3}$ our claim was based on fiscal and economic data which suggest that overall income inequalities will not be greatly reduced by the current government's policies. Comparing the socioeconomic characteristics in the areas with a total population of one million with the highest mortality in people under 65 with those in the areas with the lowest mortality, we found stark differences in poverty rates, income, wealth, education, and unemployment. ${ }^{3}$

Our updated analysis shows that even given the noticeable increases between 1981 and 1995 mortality differentials have continued to increase up to the end of 1998 (table). The standardised mortality ratio for the areas in Britain with the highest mortality in 1991-5 has increased from 178 in 1991-5 to 187 in 1996-8, and the death rate in the worst areas is now 2.64 times that in the best areas. This is despite the fact that these areas had the highest mortality in Britain in 1991-5 and regression to the mean should have led to a decline in their relative position. Nearly two third of all deaths in the worst areas would be avoided if the death rates in these areas were the same as those in the best areas.

Briefing the National Heart Forum last month, the minister for public health, Yvette Cooper, stated that "tackling inequalities and putting inequalities at the heart of government policy" is a primary aim and acknowledged that the huge health gap between the rich and the poor is "morally wrong." If the government's commitment to reducing inequalities is to be fulfilled a more concerted effort to reduce poverty and income inequalities is needed. The government has reluctantly agreed to increase the national minimum wage but by less than the increase in average earnings and hence the income gap will continue to grow. Benefits and pensions need also to be increased so that people who cannot work can share in the increased wealth and prosperity that most people in Britain are enjoying.

George Davey Smith professor of clinical

epidemiology

Department of Social Medicine, University of Bristol, Bristol BS8 2PR

Mary Shaw Economic and Social Research Council research fellow

Richard Mitchell research fellow

School of Geographical Sciences, University of Bristol, Bristol BS8 1SS

Danny Dorling professor of quantitative human geography

School of Geography, University of Leeds, Leeds LS2 9JT

David Gordon research fellow

School for Policy Studies, University of Bristol, Bristol BS8 1TZ

1 Yamey G. Study shows growing inequalities in health in Britain. BMJ 1999;319:1453. (4 December.)

2 Milburn A. Killer that shames Britain. Observer 1999 Dec $12: 13$.

3 Shaw M, Dorling D, Gordon D, Davey Smith G. The widening gap: health inequalities and policy in Britain. Bristol: Policy

4 Department of Health. "The widening gap:" Tounsend Centre Department of Health. "The widening gap:" Townsend Centre
of International Poverty Research. London: DoH, 1999. (Press of International Poverty

浆This letter has been peer reviewed.

Rapid responses e $\quad$ BMJ

Correspondence submitted electronically is available on our website www.bmj.com

Standardised mortality ratios and deaths in 1996-8 in areas of highest mortality in Britain in 1991-5

\begin{tabular}{|c|c|c|c|}
\hline Constituency & No of deaths & Standardised mortality ratio & $\%$ of avoidable deaths ${ }^{\star}$ \\
\hline Glasgow Shettleston & 790 & 248 & 71 \\
\hline Glasgow Springburn & 814 & 232 & 69 \\
\hline Glasgow Maryhill & 819 & 211 & 66 \\
\hline Glasgow Pollok & 738 & 198 & 64 \\
\hline Glasgow Anniesland & 600 & 174 & 59 \\
\hline Glasgow Baillieston & 720 & 193 & 63 \\
\hline Manchester Central & 910 & 183 & 61 \\
\hline Glasgow Govan & 621 & 194 & 63 \\
\hline Liverpool Riverside & 813 & 177 & 60 \\
\hline Manchester Blackley & 815 & 181 & 61 \\
\hline Greenock and Inverclyde & 626 & 183 & 61 \\
\hline Salford & 692 & 160 & 56 \\
\hline Tyne Bridge & 702 & 156 & 55 \\
\hline Glasgow Kelvin & 586 & 208 & 66 \\
\hline Southwark North and Bermondsey & 641 & 149 & 53 \\
\hline All & 10887 & 187 & 62 \\
\hline
\end{tabular}

*Percentage of deaths which would not have occurred if these health areas with highest mortality had same death rates as health areas with lowest mortality. 